\title{
Relationships key for new CMA president-elect
}

$\mathrm{B}$ uild relationships and the rest will follow - that's the core of Canadian Medical Association President-Elect Dr. Chris Simpson's collaborative leadership style.

Dr. Chris Simpson was acclaimed as president-elect for 2013/14 of the Canadian Medical Association (CMA) on Aug. 20 during the association's 146th annual meeting in Calgary, Alberta. Simpson takes over the role of president-elect from Dr. Louis Francescutti, the new CMA president.

Lauded by colleagues for his ability to bring disparate groups together to achieve common goals, Simpson has built a career championing improvements to patient care. Notably, his work as chair of both the Canadian Wait Time Alliance and the Canadian Cardiovascular Society's health policy and advocacy committee has led to a comprehensive set of wait-time benchmarks for all cardiovascular consultations, tests and procedures.

Simpson was the first president of the Canadian Heart Rhythm Society and now serves on the board of the Cardiac Care Network of Ontario, as well as numerous other editorial board and advisory committees. $\mathrm{He}$ is also a professor of medicine and chief of cardiology at Queen's University in Kingston, Ont., as well as medical director of the cardiac programs at Kingston General Hospital.

Simpson joined $C M A J$ by phone to share his vision of "consultative leadership" and agenda for his coming term as president.

CMAJ: What attracted you to bid for CMA's leadership?

Simpson: I've just been so impressed with what the CMA has done with its health care transformation agenda ... and its determination to take the whole discussion above and beyond the traditional role that doctors have played. I find it very noble, and

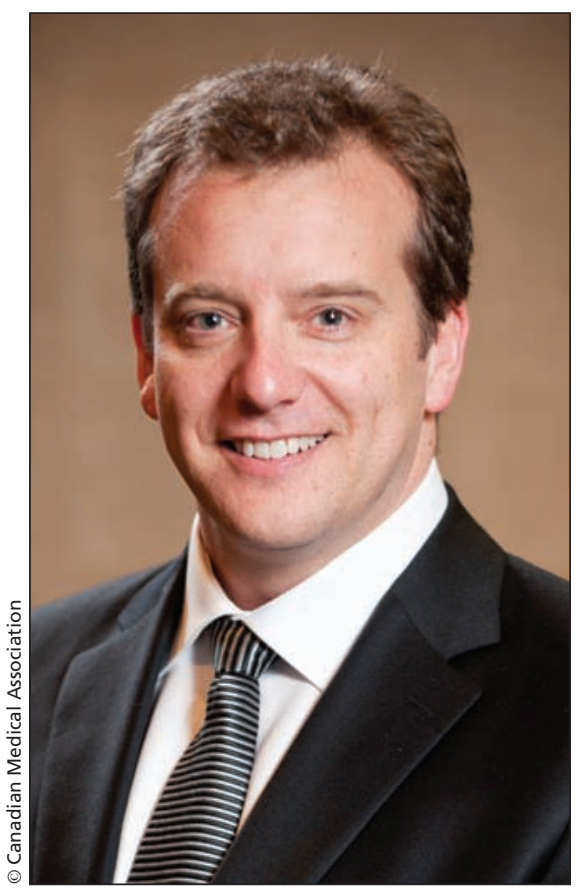

New Canadian Medical Association President-Elect Dr. Chris Simpson aims to build bridges with government and between physicians.

this is an exciting time for us to change how we conceptualize what health is and transition to a system that achieves it.

CMAJ: You've identified building the reputation of Canada's doctors as a top priority: Where do you see room for improvement?

Simpson: The last few years have seen lots of ... missed opportunities ... between government and physician groups ... so I would like to develop [partnerships] between the medical organizations and the federal and provincial governments ... based on personal relationships and trust. ... I know there's a lot of history and value that can come from an adversarial process, but I don't think we have time for that anymore.

CMAJ: How can CMA be more collaborative?
Simpson: I draw on some of the lessons from my work with the Wait Time Alliance. ... We treat the government very respectfully, ... we tell them in advance exactly what our methodology is going to be, we report their own data back to them, ... and that "How can we help you?" kind of attitude ... can really go a long way.

CMAJ: You've also stressed the need to rebuild bridges between primary care, family medicine and specialists - what's behind this communication breakdown?

Simpson: Both literally and metaphorically, we've lost the doctors' lounge, that place where everybody got together, got to know each other socially and understood each other. ... Now we have teams, sub-specialists, sub-sub-specialists and other health care practitioners who are in the mix, and the complexity of the patient experience is reflected in the complexity of how we interact with each other.

CMAJ: What first steps can CMA make toward a national health human resources plan?

Simpson: The opportunity for the CMA is to ... create a health human resources observatory, a place where we can assemble all of the information that's currently out there ... because a lot of the distribution problems can be auto-fixed simply by letting people know, for example, there's a need for this kind of specialist here and not there.

CMAJ: What unique challenges will the renewal of the 2004 health accord pose for your term?

Simpson: We'll need to talk about how we're going to define what the federal role should be ... but it doesn't matter a whole lot at the end of the day if it's the federal or provincial governments 
[providing the funds] as long as health improves. ... I think we need to have some flexibility in thought about what we're willing to consider the structure should be.

CMAJ: What would you identify as the lesson learned from the last accord?

Simpson: The last 10 years have taught us that throwing money at the situation allows us to tread water but really hasn't effected change - that requires a whole lot more partnership and elbow grease.

CMAJ: Where do you stand on moving toward a more privately funded model of health care?

Simpson: My concern has always been that we're not able to have a good conversation about this because of the power of the labels attached, but ... I believe very strongly in the ability of the [current] system to deliver equitable health care to Canadians ... and I'd much rather focus on improving the structure we have than talk about revolutionarily changing that structure. Lauren Vogel, CMAJ

CMAJ 2013. DOI:10.1503/cmaj.109-4572 